\title{
FUNGOLÂNDIA: JOGO EDUCATIVO DE TABULEIRO SOBRE A DIVERSIDADE E IMPORTÂNCIA DOS FUNGOS NA CAATINGA
}

\author{
Isnara Evelin Barbosa da Silva ${ }^{1}$ \\ Laís Alanna de Sá Jardim² \\ Elâine Maria dos Santos Ribeiro ${ }^{3}$ \\ Regina Lúcia Félix de Aguiar Lima ${ }^{4}$
}

Resumo: Os fungos estão distribuídos em todos os ecossistemas da biosfera, onde atuam principalmente como decompositores da matéria orgânica e na ciclagem biogeoquímica. Apesar de sua importância e distribuição, sua presença nos ecossistemas nem sempre é percebida, pois há espécies micro e macroscópicas. Visando contribuir para o conhecimento a diversidade dos fungos e seus serviços ecossistêmicos na Caatinga, foi desenvolvido o jogo de tabuleiro Fungolândia, destinado à educação básica. Fungolândia apresenta algumas espécies de fungos que ocorrem na Caatinga e o papel que podem desempenhar em ambientes naturais e urbanos. O jogo é uma ferramenta didática para o professor e contribui para o aprendizado de forma lúdica.

Palavras-chave: Reino Fungi; Ferramenta Didática; Serviços Ecossistêmicos; Educação Ambiental; Metodologias Ativas.

Abstract: Fungi are distributed in all ecosystems in the biosphere, where they act mainly as decomposers of organic matter and in biogeochemical cycling. Despite its importance and distribution, its presence in ecosystems is not always noticed, as there are micro and macroscopic species. Aiming to contribute to the knowledge of the diversity of fungi and their ecosystem services in the Caatinga, the board game Fungolândia was developed for basic education. Fungolândia presents some species of fungi and the role they can play in natural and urban environments, allows learning in a fun way and assists the teacher in addressing this theme at school.

Keywords: Fungi Kingdom; Didactic Tool; Ecosystem Services; Environmental Education; Active Methodologies.

\footnotetext{
${ }^{1}$ Universidade de Pernambuco. E-mail: isnara.evelin@upe.br. http://lattes.cnpq.br/1763985618690395

${ }^{2}$ Universidade de Pernambuco. E-mail: lais.jardim@upe.br. http://lattes.cnpq.br/2806204416608762

3 Universidade de Pernambuco. E-mail: elaine.ribeiro@upe.br. http://lattes.cnpq.br/3304685448889789

${ }^{4}$ Universidade de Pernambuco. E-mail: regina.aguiar@upe.br. http://lattes.cnpq.br/8549101690272163
}

Revbea, São Paulo, V. 15, № 6: 52-99, 2020.

revista brasileira educação ambiental 


\section{Introdução}

O Reino Fungi é constituído tanto por organismos microscópicos quanto por macroscópicos. Eles estão presentes em todos os ecossistemas da biosfera, onde atuam principalmente na decomposição da matéria orgânica (ESPOSITO; AZEVEDO, 2010). Espécies que formam estruturas macroscópicas são mais conhecidas, sendo chamados genericamente de cogumelos e orelhas de pau (ESPOSITO; AZEVEDO, 2010; MAIA, 2014). Algumas espécies microscópicas são percebidas somente pelos efeitos produzidos, como apodrecimento de frutas, doenças nas plantas e reações alérgicas ao mofo (MAIA, 2014).

A Caatinga é um ecossistema brasileiro, que costuma estar associado à seca, pobreza e baixa biodiversidade biológica, mas ele tem importante valor biológico e econômico (FREIRE et al. 2018). Ela possui grande diversidade de fungos, que, por sua vez, realizam inúmeros serviços ecossistêmicos e, para conservá-los, a melhor maneira é através da educação (SILVA, 2014). A Caatinga ocorre no semiárido brasileiro, região marcada por médias anuais altas para temperatura $\left(25\right.$ a $\left.30^{\circ} \mathrm{C}\right)$ e baixas para pluviosidade $(800 \mathrm{~mm}$ ao ano). As chuvas têm distribuição temporal restrita a três ou quatro meses por ano, com distribuição espacial irregular (SILVA, 2014; FREIRE et al. 2018). Além disso, apresenta alto índice de insolação, com sol forte quase todos os dias do ano (TEIXEIRA, 2016). Em ambientes naturais, o aparecimento dos corpos de frutificação dos fungos, que são as porções macroscópicas conhecidas como cogumelos ou orelhas de pau, está relacionado com a taxa de umidade do ar e do solo decorrentes da ocorrência de chuvas. Assim, na Caatinga, as condições ambientais são limitantes para a formação de cogumelos, estruturas de reprodução dos fungos e, portanto, a percepção de fungos macroscópicos fica limitada aos períodos chuvosos (DRECHSLERSANTOS et al. 2010; MAIA, 2014).

Os seres vivos de um ecossistema prestam diversos serviços ecossistêmicos, que são os benefícios realizados pela natureza e que dão suporte à vida no planeta (PEIXOTO; LUZ; BRITO, 2016), tais como ciclagem de nutrientes e de água, formação e renovação dos solos, controle de pragas, tratamento de resíduos, produção de alimentos (BRASIL, 2018). Os fungos contribuem para a realização de muitos desses serviços e, por serem frequentemente microscópicos, geralmente, passam despercebidos nos ecossistemas. Além dos serviços ecossistêmicos já citados, os fungos têm papel reconhecido na produção de medicamentos, bebidas e alimentos, como a penicilina, cerveja e queijo (PEIXOTO; LUZ; BRITO, 2016).

A utilização de jogos didáticos, de maneira geral, nas escolas, não é novidade, porém abordando a Educação Ambiental (EA) sim, algo que se faz necessário para o estudante conhecer o ambiente circundante e entender seu significado, sendo uma ferramenta imprescindível (FALKOSKI, 2020). A Lei no 9.795, de 27 de abril de 1999, institui que a Política Nacional de Educação Ambiental menciona que a EA deve ocorrer de forma articulada em todos os 
níveis escolares, em caráter formal e não formal, visando ao pluralismo de ideias pedagógicas na perspectiva inter, multi e transdisciplinar (BRASIL, 1999).

A inserção de jogos na prática pedagógica objetiva desenvolver, nos alunos do Ensino Fundamental, a capacidade de resolução de problemas, de pensamento lógico e de abstração (MIRANDA, 2001). A EA pode ser utilizada com ferramenta para sensibilização e abordagem de temas importantes no ambiente escolar, e o uso de jogos educativos é uma alternativa para despertar reflexão, criticidade e interesse no aprendizado. Com os jogos, o aprendizado pode se tornar prazeroso e formar cidadãos conscientes do seu papel, e preparados para buscarem alternativas e soluções sustentáveis para manter o meio ambiente equilibrado. Os conhecimentos difundidos a partir de práticas de EA permitem a construção de uma visão de mundo mais articulada e menos fragmentada, contribuindo para que o indivíduo se veja como participante de um mundo em constante transformação (MIRANDA, 2001). Para realizar EA, é necessário que se tenha percepção do ambiente, das pessoas e das relações estabelecidas com ele (REIGOTA, 2017), visto que o aluno se utiliza desses conceitos em toda sua vivência.

Nesse contexto, o objetivo nesse trabalho é apresentar um jogo educativo desenvolvido para alunos do Ensino Fundamental sobre conhecimento da biodiversidade e serviços ecossistêmicos dos fungos na Caatinga.

\section{Jogos educativos para o conhecimento da biodiversidade e ecologia dos fungos da Caatinga}

$\mathrm{Na}$ construção de jogos educativos, é importante incluir o fornecimento de informação, além de evitar despertar competição excessiva e que seja realizado de forma sadia dentro do ambiente de sala de aula ou da escola (BREDA; PICANÇO, 2015). Formular mecanismos no jogo que sejam relacionados com o ecossistema local é uma maneira de trazer novas informações de forma dinâmica para as crianças (MIRANDA, 2001), bem como para promover a construção do conhecimento científico sobre determinado ecossistema de forma agradável para os discentes (MENEZES et al. 2016). O conhecimento sobre o reino Fungi é um tema desafiador na educação básica, pois esse grupo é formado de espécies macroscópicas e microscópicas, com taxonomia variável que ainda não está totalmente elucidada e devido também à complexidade e diversidade das estruturas morfológicas e reprodutivas dos diversos grupos (STOFELL et al. 2016).

A Caatinga é uma região de floresta seca, que está incluída no semiárido brasileiro, abrange municípios de todos os estados do Nordeste e do norte de Minas Gerais (TABARELLI et al. 2018). A área da Caatinga é oficialmente de $844.453 \mathrm{~km}^{2}$, segundo o Ministério do Meio Ambiente do Brasil (BRASIL, 2020; FREIRE et al. 2018), ou de 912.529 km² conforme proposição 
em revisão recente (SILVA; LEAL; TABARELLI., 2017). Sua diversidade de fauna e flora a tornam única em todo o mundo, segundo a Associação Caatinga, pois, mesmo tendo semelhanças com o semiárido do Chile e de países da Ásia e África, a Caatinga possui espécies exclusivas (ASSOCIAÇÃO CAATINGA, 2020). No Brasil, são registrados em torno de 5500 espécies de fungos, sendo 850 delas já encontradas na Caatinga. Muitas ainda são desconhecidas e correm o risco de serem extintas antes mesmo de sua descoberta (MAIA, 2014). Apesar de sua reconhecida importância, o ecossistema vem sendo amplamente modificado, principalmente por perturbações antrópicas com retirada da vegetação para produção de lenha, atividade agrícola com implantação de monoculturas, áreas de pasto para forrageio animal (SILVA et al. 2010). Essas ações causam desequilíbrio ambiental e dificultam sua recuperação (BRASIL, 2020). As perturbações afetam também os fungos, que não conseguem realizar todos os processos biológicos de maneira adequada, como a ciclagem de nutrientes, decomposição de material orgânico, atividade enzimática, influenciando diretamente na própria existência humana, que não seria possível sem eles (SILVA; MALTA, 2016).

Sabe-se que preservação do meio ambiente é uma preocupação da sociedade em relação às ações antrópicas que causam impactos ambientais. Segundo o CONAMA (1986, p.1)

Denomina-se impacto ambiental qualquer alteração das propriedades físicas, químicas e biológicas do meio ambiente, causada por qualquer forma de matéria ou energia resultante das atividades humanas que, direta ou indiretamente, afetam a saúde, a segurança e o bem-estar da população; as atividades sociais e econômicas; a biota e a qualidade dos recursos ambientais. 
serviços ecossistêmicos no ensino escolar sob a forma de jogo didático, com o objetivo de formarmos sujeitos do conhecimento, despertando nos alunos o interesse em entender e refletir sobre a importância dos fungos.

Em ambientes naturais, os fungos podem ter vida livre, sendo sapróbios, ou viverem associados a outros seres vivos, sendo simbionte. Os sapróbios produzem enzimas digestivas e as liberam no meio externo. Essas enzimas digerem a matéria orgânica no entorno do fungo, que depois se alimenta absorvendo o material digerido (ESPOSITO; AZEVEDO, 2010). Esses fungos são fundamentais na ciclagem da matéria e manutenção do equilíbrio dos ecossistemas. A principal função desses organismos no solo é a degradação da matéria orgânica, como celulose e lignina, gerando biomassa proteica, e alguns podem ser utilizados na alimentação humana, como é o caso dos cogumelos champignon e shitake (KAVANAGH, 2005; ESPOSITO; AZEVEDO, 2010).

Os fungos simbiontes, que se associam com organismos de espécies diferentes, podem estabelecer relações de dois tipos: mutualista quando a associação é benéfica para ambos os participantes envolvidos ou parasitismo quando é benéfica para um dos participantes e prejudicial para o outro (SMITH; READ, 2008). Os principais exemplos de simbiose mutualistas que os fungos estabelecem são as micorrizas e os líquens. Micorrizas são associação de fungos de diversos grupos com plantas de diversas espécies. No estabelecimento da associação micorrízica, os fungos são beneficiados pelo fornecimento de fotossintatos pelas plantas que, em troca, têm aumento na capacidade de absorção de água e nutrientes do solo. Essa simbiose tem utilização potencial para recuperação de áreas degradadas e na agricultura orgânica ou de base sustentável (LIMA et al. 2013; STOFELL et al. 2016).

Os liquens são associações mutualísticas entre fungos (geralmente espécies de ascomicetos) e algas (BARBOSA-SILVA et al. 2019). Nessas associações, os fungos recebem os nutrientes fornecidos pelas algas; em troca, proporcionam a elas um ambiente protegido, com acesso a minerais e água necessários para o seu desenvolvimento (SPIELMANN, 2006). Eles são considerados seres pioneiros, pois são os primeiros a se instalar em alguns ambientes, como sobre rochas (BARBOSA-SILVA et al. 2019). São considerados bioindicadores de qualidade ambiental e parâmetro de diversidade, pois absorvem determinadas substâncias como dióxido de carbono e as retêm, por isso sua ausência indica que o ambiente está poluído (LUCHETA et al. 2018; SPIELMANN, 2006).

Os fungos parasitas se alimentam de substâncias de organismos vivos e são conhecidos por causar doenças no ser humano e em vegetais (MAIA, 2014), como exemplo a antracnose, que acomete as plantas através do Colletotrichum sp., frequente em diversas culturas, causando necrose do caule, manchas nas folhas e frutos (DOMICIANO, 2019). 
Quadro 1: Fungos que ocorrem na Caatinga, suas principais características estruturais e ecológicas e seus efeitos benéficos e maléficos.

\begin{tabular}{|c|c|c|c|}
\hline $\begin{array}{l}\text { Fungos - } \\
\text { Grupos Espécie }\end{array}$ & Características & Benefícios & Malefícios \\
\hline $\begin{array}{l}\text { Ascomicetos } \\
\text { Penicillium sp. }\end{array}$ & $\begin{array}{l}\text { - Espécie conhecida } \\
\text { como mofos ou } \\
\text { bolores. } \\
\text { - São seres } \\
\text { microscópicos, } \\
\text { possuem geralmente } \\
\text { coloração verde ou } \\
\text { preta. } \\
\text { - Estão presentes no } \\
\text { solo, plantas, } \\
\text { alimentos. }\end{array}$ & $\begin{array}{l}\text { - Contribuem para a } \\
\text { decomposição de matéria } \\
\text { orgânica vegetal e deixam } \\
\text { os solos mais férteis. } \\
\text { - Usados na produção de } \\
\text { medicamentos como } \\
\text { antibióticos (penicilina), } \\
\text { antifúngicos e antitumorais; } \\
\text { - Produção de queijos; }\end{array}$ & $\begin{array}{l}\text { Atuam na } \\
\text { decomposição de } \\
\text { alimentos } \\
\text { diversos, } \\
\text { deixando-os } \\
\text { mofados ou } \\
\text { embolorados. }\end{array}$ \\
\hline $\begin{array}{l}\text { Ascomiceto } \\
\text { Saccharomyces } \\
\text { cerevisiae }\end{array}$ & $\begin{array}{l}\text { - Espécie conhecida } \\
\text { como levedura de } \\
\text { cerveja } \\
\text { - São seres } \\
\text { unicelulares e } \\
\text { microscópicos. }\end{array}$ & $\begin{array}{l}\text { - Podem ser usados em } \\
\text { processos industriais } \\
\text { diversos como a produção } \\
\text { de alimentos como cerveja, } \\
\text { de pães; } \\
\text { - Podem ser usados na } \\
\text { produção de } \\
\text { biocombustíveis, como } \\
\text { bioquerosene e biodiesel. }\end{array}$ & \\
\hline $\begin{array}{l}\text { Basidiomiceto } \\
\text { Agaricus } \\
\text { bisporus }\end{array}$ & $\begin{array}{l}\text { - Espécie forma } \\
\text { cogumelos chamados } \\
\text { de champignon. } \\
\text { - São macroscópicos, } \\
\text { podem ser cultivados } \\
\text { com uso de compostos } \\
\text { orgânicos. }\end{array}$ & $\begin{array}{l}\text { - Usados na alimentação e } \\
\text { na produção de conservas. } \\
\text { - Nutritivos por serem ricos } \\
\text { em proteínas, fibras e } \\
\text { vitaminas do complexo B. }\end{array}$ & \\
\hline $\begin{array}{l}\text { Basidiomiceto } \\
\text { Podaxis pistillaris }\end{array}$ & $\begin{array}{l}\text { Espécie macroscópica } \\
\text { forma cogumelos. } \\
\text { Formados na matéria } \\
\text { orgânica em } \\
\text { decomposição. }\end{array}$ & $\begin{array}{l}\text { - Realiza decomposição de } \\
\text { matéria orgânica vegetal. } \\
\text { - Pode ser usado na } \\
\text { alimentação humana por } \\
\text { ser rico em proteínas. }\end{array}$ & \\
\hline $\begin{array}{l}\text { Basidiomiceto } \\
\text { Pycnoporus } \\
\text { sanguineus }\end{array}$ & $\begin{array}{l}\text { Espécie macroscópica } \\
\text { de cor laranja, que } \\
\text { ocorre em troncos em } \\
\text { decomposição. } \\
\text { Conhecida como } \\
\text { orelha de pau ou } \\
\text { urupê, que, na língua } \\
\text { guarani, significa } \\
\text { sangue de madeira. }\end{array}$ & $\begin{array}{l}\text { - Realiza decomposição de } \\
\text { vegetais e ciclagem de } \\
\text { nutrientes. } \\
\text { - Contribui para a } \\
\text { degradação de } \\
\text { substâncias. } \\
\text { - Usada para tratar } \\
\text { resíduos da indústria têxtil, } \\
\text { produção de papel, de } \\
\text { pesticidas; } \\
\text { - Tem propriedades } \\
\text { medicinais. }\end{array}$ & $\begin{array}{l}\text { - Destrói madeira } \\
\text { e objetos de } \\
\text { madeira, como } \\
\text { toras para } \\
\text { marcenaria, } \\
\text { cercas, bancos, } \\
\text { portas. }\end{array}$ \\
\hline
\end{tabular}


...continuação.

\begin{tabular}{|c|c|c|c|}
\hline $\begin{array}{l}\text { Fungos - } \\
\text { Grupos Espécie }\end{array}$ & Características & Benefícios & Malefícios \\
\hline $\begin{array}{l}\text { Deuteromiceto } \\
\text { Oidium sp. }\end{array}$ & $\begin{array}{l}\text { Espécie microscópica. } \\
\text { Encontrada em plantas, } \\
\text { principalmente mais } \\
\text { jovens. }\end{array}$ & & $\begin{array}{l}\text { - Causa doença } \\
\text { nas folhas das } \\
\text { plantas, mofo e } \\
\text { manchas pardas; - } \\
\text { Retira nutrientes da } \\
\text { planta e provoca } \\
\text { nanismo. }\end{array}$ \\
\hline $\begin{array}{c}\text { Deuteromiceto } \\
\text { Alternaria sp. }\end{array}$ & $\begin{array}{l}\text { Espécie microscópica. } \\
\text { Encontrado no solo, água, } \\
\text { objetos, construções; }\end{array}$ & & $\begin{array}{l}\text { - Causa doença de } \\
\text { planta, } \\
\text { caracterizada pela } \\
\text { presença de } \\
\text { manchas escuras } \\
\text { nas folhas, } \\
\text { desfolhamento. } \\
\text { - Causa alergia em } \\
\text { humanos. }\end{array}$ \\
\hline $\begin{array}{l}\text { Deuteromiceto } \\
\text { Colletotrichum } \\
\text { sp. }\end{array}$ & $\begin{array}{l}\text { Espécie microscópica. } \\
\text { Encontrado em ramos, } \\
\text { folhas e frutos de plantas. }\end{array}$ & & $\begin{array}{l}\text { Causa a } \\
\text { antracnose, doença } \\
\text { de planta, } \\
\text { caracterizada pela } \\
\text { presença de } \\
\text { manchas nas } \\
\text { folhas, } \\
\text { desfolhamento, } \\
\text { diminuição da } \\
\text { produção vegetal. }\end{array}$ \\
\hline $\begin{array}{l}\text { Glomeromicetos } \\
\text { Fungos } \\
\text { micorrízicos } \\
\text { arbusculares }\end{array}$ & $\begin{array}{l}\text { Fungos microscópicos } \\
\text { que vivem associados às } \\
\text { raízes das plantas, numa } \\
\text { simbiose chamada } \\
\text { micorriza arbuscular. } \\
\text { Ajudam as raízes no } \\
\text { processo de absorção. }\end{array}$ & $\begin{array}{l}\text { - Aumentam a absorção } \\
\text { de água e sais minerais } \\
\text { pelas plantas. } \\
\text { - Aumentam a } \\
\text { resistência das plantas à } \\
\text { estresse ambiental e } \\
\text { aos patógenos. }\end{array}$ & \\
\hline $\begin{array}{l}\text { Líquens } \\
\text { fungos } \\
\text { ascomicetos } \\
\text { associados a } \\
\text { algas }\end{array}$ & $\begin{array}{l}\text { Visíveis a olho nu, o uso } \\
\text { de lupa de mão ajuda na } \\
\text { visualização. } \\
\text { Em ambientes naturais, } \\
\text { crescem sobre folhas, } \\
\text { cascas de árvore rochas, } \\
\text { solos. } \\
\text { Ocorrem em ambientes } \\
\text { diversos, até em locais } \\
\text { com temperaturas } \\
\text { extremas. }\end{array}$ & $\begin{array}{l}\text { - Produção de perfumes } \\
\text { e medicamentos; } \\
\text { - Transformação de } \\
\text { rocha em solo; } \\
\text { - Sua presença é uma } \\
\text { indicação de não } \\
\text { contaminação por } \\
\text { produtos químicos em } \\
\text { um ambiente; } \\
\text { - Servem de alimento } \\
\text { para alguns animais, } \\
\text { como cupins e outros. }\end{array}$ & \\
\hline
\end{tabular}

Continua..

Revbea, São Paulo, V. 15, № 6: 52-99, 2020. 


....continuação.
\begin{tabular}{|l|l|l|l|}
\hline $\begin{array}{l}\text { Fungos - } \\
\text { Grupos Espécie }\end{array}$ & Características & Benefícios & Malefícios \\
\hline $\begin{array}{l}\text { Zigomicetos } \\
\text { Pilobolus sp. }\end{array}$ & $\begin{array}{l}\text { Visível a olho nu; o uso de } \\
\text { lupa de mão ajuda na } \\
\text { visualização. } \\
\text { Na natureza crescem } \\
\text { sobre folhas, cascas de } \\
\text { árvore, rochas, solos, } \\
\text { fezes. } \\
\text { Ocorrem em ambientes } \\
\text { diversos, inclusive com } \\
\text { temperaturas extremas. }\end{array}$ & $\begin{array}{l}\text { Realizam a } \\
\text { decomposição de } \\
\text { excrementos (fezes e } \\
\text { esterco) de animais, e } \\
\text { contribuem para a } \\
\text { nutrição do solo e a } \\
\text { ciclagem de nutrientes. }\end{array}$ & $\begin{array}{l}\text { Podem causar } \\
\text { doenças em } \\
\text { animais, humanos } \\
\text { e plantas. }\end{array}$ \\
& & \\
\end{tabular}

Fonte: Autoria própria, com base em Maia et al. 2014 e Putzke, 2015.

Além dessas ações em ambientes naturais, podemos citar a aplicação que fazemos de diversas espécies de fungos em variados setores da economia. As leveduras, que são usadas para a fabricação de pães, queijos e bebidas alcoólicas, como vinho e cerveja. Há espécies de fungos utilizados na indústria farmacêutica, alimentícia, na recuperação de áreas degradadas, no controle de pragas (KAVANAGH, 2005; ESPOSITO; AZEVEDO, 2010).

\section{Metodologia}

Para a criação do jogo sobre fungos que ocorrem na Caatinga, inicialmente, foi feito um levantamento da biodiversidade fúngica da Caatinga (MAIA et al. 2014). Depois disso, foi elaborado um jogo de tabuleiro e cartas, buscando-se um formato dinâmico, para o qual foram criadas regras.

O jogo foi denominado Fungolândia; é constituído por 4 grupos de cartas, um tabuleiro e um cartaz com as regras. O tabuleiro construído contém uma vila com uma parte urbana e uma parte rural, com diferentes ambientes e estabelecimentos. $O$ tabuleiro pode ser ampliado e impresso, usando-se 4 folhas de papel tamanho A4.

Foram criados quatro grupos de cartas. São elas: (1) cartas de missão; (2) cartas de fungos vilões; (3) cartas de vegetação e; (4) cartas de recompensa. As cartas dos três primeiros grupos têm dimensões iguais entre si, com área de $5 \times 8,5 \mathrm{~cm}$, enquanto as cartas de recompensa são quadrados, e menores $(5 \times 5 \mathrm{~cm})$. Para os diferentes grupos de cartas, devem ser impressas diferentes quantidades de cartas para proporcionar variação qualitativa e quantitativa da dinâmica do jogo (Tabela 1), totalizando 30 cartas de missões, 6 cartas de fungos vilões, 4 cartas de recompensa da vegetação e 15 cartas de recompensa.

As espécies ou grupos de fungos que são utilizados nas cartas do jogo 
Nesse conteúdo estarão incluídas e caracterizadas as espécies e grupos de fungos incluídas no jogo e relacionadas nas cartas. As imagens utilizadas nas cartas são de bancos de dados gratuitos, disponíveis nos sites Canva e Pixabay.

Tabela 1: Grupos de cartas, tipos de cartas e quantidade do jogo Fungolândia

\begin{tabular}{|c|c|c|}
\hline GRUPO & TIPO DE CARTAS & QUANTIDADE \\
\hline \multirow[t]{8}{*}{ Missões } & Agaricus bisporus & 5 \\
\hline & Fungos micorrízicos arbusculares & 9 \\
\hline & Liquens & 3 \\
\hline & Penicillium & 2 \\
\hline & Pilobolus & 4 \\
\hline & Podaxis pistillaris & 1 \\
\hline & Pycnoporus sanguineus & 4 \\
\hline & Saccharomyces cerevisiae & 2 \\
\hline \multirow[t]{3}{*}{ Fungos vilões } & Alternaria sp. & 2 \\
\hline & Colletotrichum sp. & 2 \\
\hline & Oidium sp. & 2 \\
\hline \multirow[t]{4}{*}{ Vegetação } & $\begin{array}{l}\text { Anadenanthera colubrina (Vell.) Brenan } \\
\text { (Nome popular: Angico) }\end{array}$ & 1 \\
\hline & $\begin{array}{l}\text { Myracrodruon urundeuva Allemão } \\
\text { (Nome popular: Aroeira) }\end{array}$ & 1 \\
\hline & $\begin{array}{l}\text { Cenostigma pyramidale (Tul.) Gagnon \& G.P.Lewis } \\
\text { (Nome popular: Catingueira) }\end{array}$ & 1 \\
\hline & $\begin{array}{l}\text { Amburana cearensis Allemão } \\
\text { Nome popular: Umburana) }\end{array}$ & 1 \\
\hline \multirow[t]{14}{*}{ Recompensas } & Antibiótico & 1 \\
\hline & Biodiesel & 1 \\
\hline & Cerveja & 1 \\
\hline & Excremento decomposto & 1 \\
\hline & Local perfeito sem produtos tóxicos & 1 \\
\hline & Ticket refeição - Champignon & 1 \\
\hline & Produção agrícola: feijão & 1 \\
\hline & Produção agrícola: milho & 1 \\
\hline & Produção agrícola: acerola & 1 \\
\hline & Produção agrícola: manga & 1 \\
\hline & Pães & 2 \\
\hline & Queijo de cabra & 1 \\
\hline & Resíduos da fábrica de tecido tratado & 1 \\
\hline & Vegetais decompostos & 1 \\
\hline
\end{tabular}

Fonte: Autoria própria.

A construção do jogo incluiu o desenvolvimento de um tabuleiro e a elaboração de cartas com uso de ferramentas digitais do Canva (www.canva.com), que é um aplicativo com uso gratuito que permite a elaboração de material gráfico variado com possibilidade de importação em diversos formatos. 
O jogo Fungolândia tem como público alvo crianças e adolescentes, estudantes do $6^{\circ}$ ao $9^{\circ}$ ano do ensino fundamental e faz parte do projeto "Aprendendo sobre o valor da biodiversidade da Caatinga e seus serviços ecossistêmicos no ensino escolar" apoiado pela Fundação de Amparo à Ciência e Tecnologia do Estado de Pernambuco (APQ - 0177-2.05/18). Não foi possível testar este recurso didático em ambiente escolar devido às mudanças ocorridas em 2020 no ensino presencial como consequência da pandemia de COVID-19.

\section{Resultados e discussão}

\section{Apresentação do jogo}

O jogo Fungolândia possui 4 grupos de cartas, que, juntas, totalizam 55 cartas, um tabuleiro e um cartaz com as regras. Os quatro grupos de cartas são: cartas das missões dos fungos (30 unidades), cartas de fungos vilões (6 unidades), cartas de vegetação (4 unidades) e cartas de recompensas (15 unidades). As cartas produzidas têm, no verso, uma ilustração de cogumelo e, na frente, figuras e informações ou instruções (Figura 1).

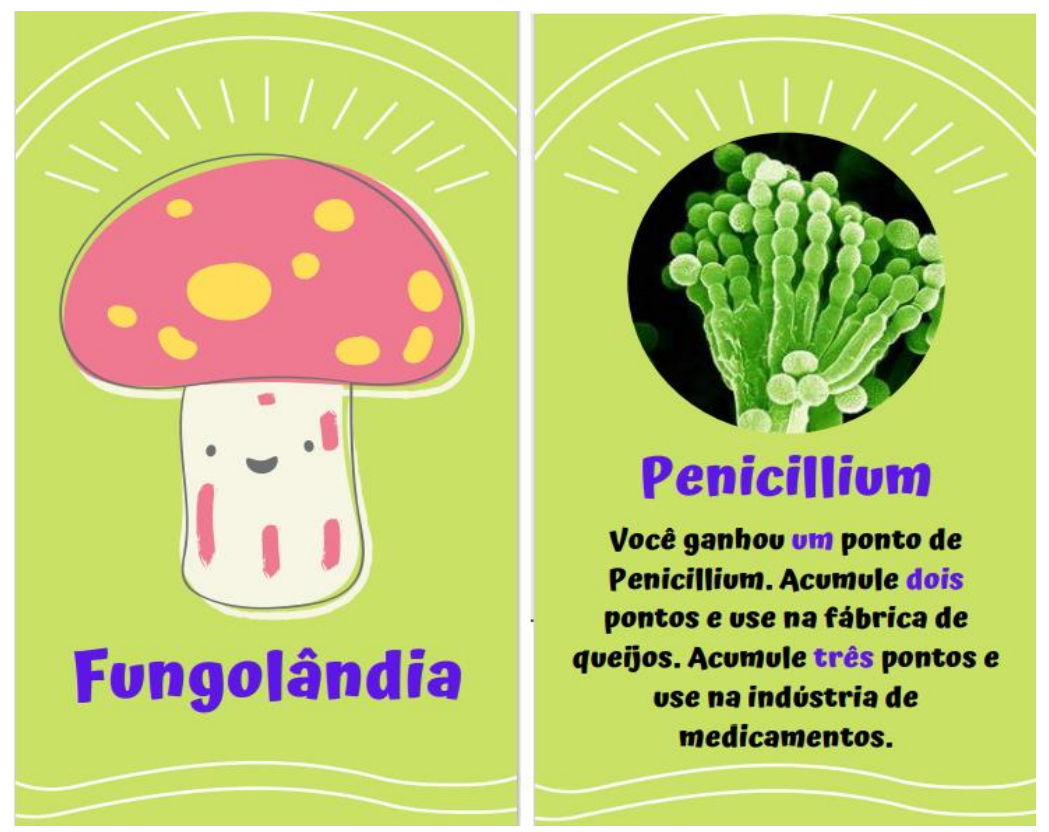

Figura 1: Modelo de carta, com verso (cogumelo) e frente (figura e texto), do Fungolândia: jogo educativo de tabuleiro sobre a diversidade e importância dos fungos na Caatinga.

Fonte: Autoria própria. 


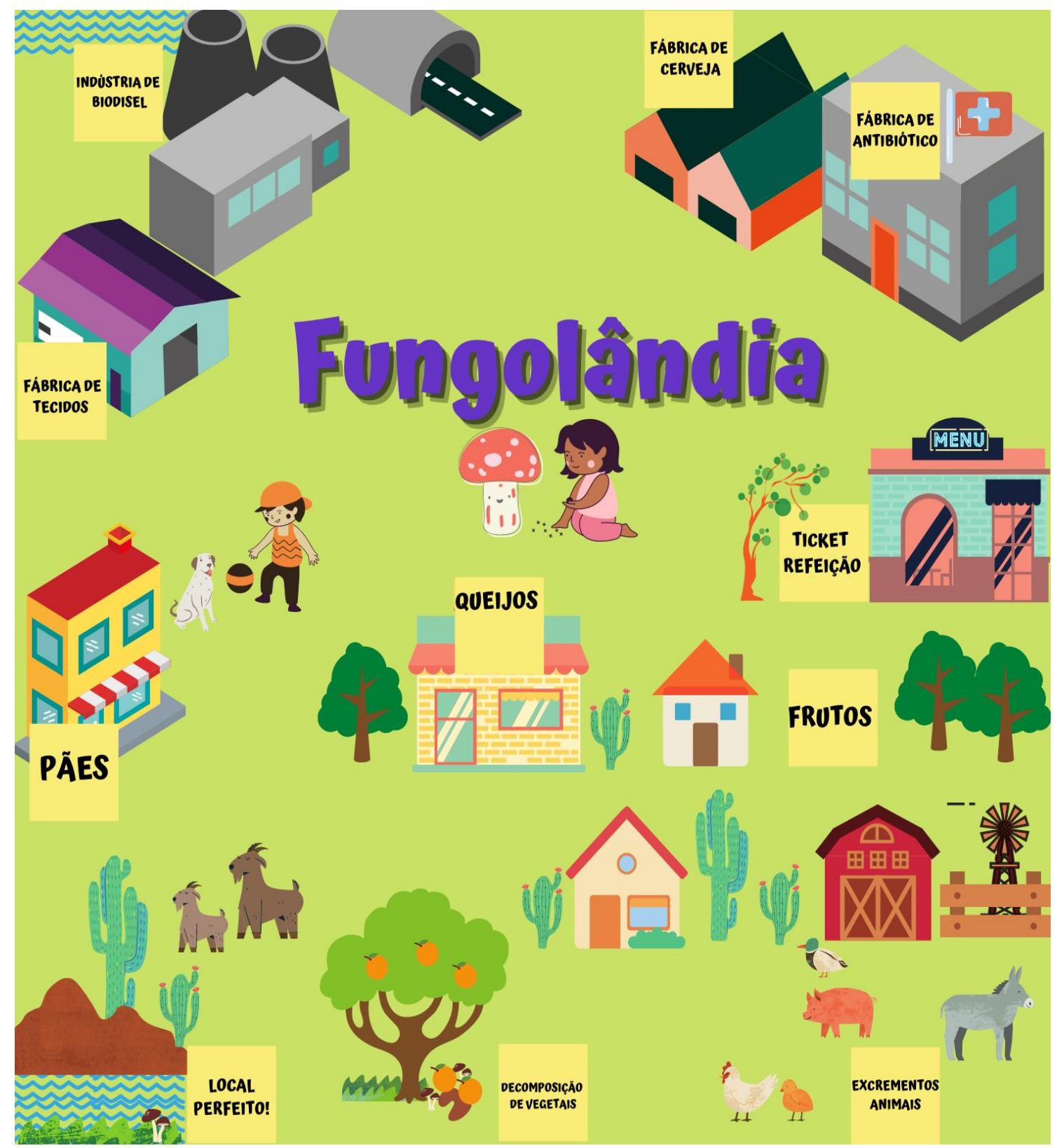

Figura 2: Tabuleiro do Fungolândia: jogo educativo de tabuleiro sobre a diversidade e importância dos fungos na Caatinga.

Fonte: Autoria própria.

Durante o jogo, as cartas de missão, vegetação e de fungos vilões deverão estar juntas e empilhadas ao lado do tabuleiro. Essas cartas têm o mesmo tamanho e estrutura semelhante, pois, de um modo geral, mostram figuras ou fotos de espécies de fungos, grupos de fungos ou de plantas da Caatinga selecionadas para a inclusão no jogo, seguida do nome da espécie e de instruções para o uso da carta no jogo. As cartas de recompensas estarão dispostas no tabuleiro, nos diversos ambientes representados, sendo colocadas nos quadrados com os nomes de cada ambiente. 


\section{Descrição dos grupos de cartas}

As cartas criadas para o jogo podem ser agrupadas em 4 tipos: cartas das missões dos fungos, cartas de fungos vilões, cartas de vegetação e cartas de recompensas. As cartas dos três primeiros tipos tem mesmo formato, mesmo verso e devem ficar empilhadas juntas. Após serem embaralhadas, devem ser colocadas ao lado do tabuleiro. Enquanto as cartas do último tipo tem formato quadrado, verso diferente e devem ficar distribuídas no tabuleiro.

\section{Cartas de fungos vilões}

As cartas de fungos vilões trazem espécies de fungos que causam doenças em plantas, ou seja, de fungos fitopatogênicos. Elas podem ser usadas contra os adversários e atrapalharão em algum processo da vila ou na área com vegetação nativa. Então, caso o adversário tenha conseguido uma recompensa, o fungo vilão a anula e a recompensa volta para o tabuleiro.

Foram elaborados 3 tipos diferentes de cartas de fungos vilões. Elas contêm a imagem de plantas infectadas com essas espécies de fungos. Devem-se imprimir 2 cartas de cada tipo, totalizando 6 cartas desse grupo (Figura 3).
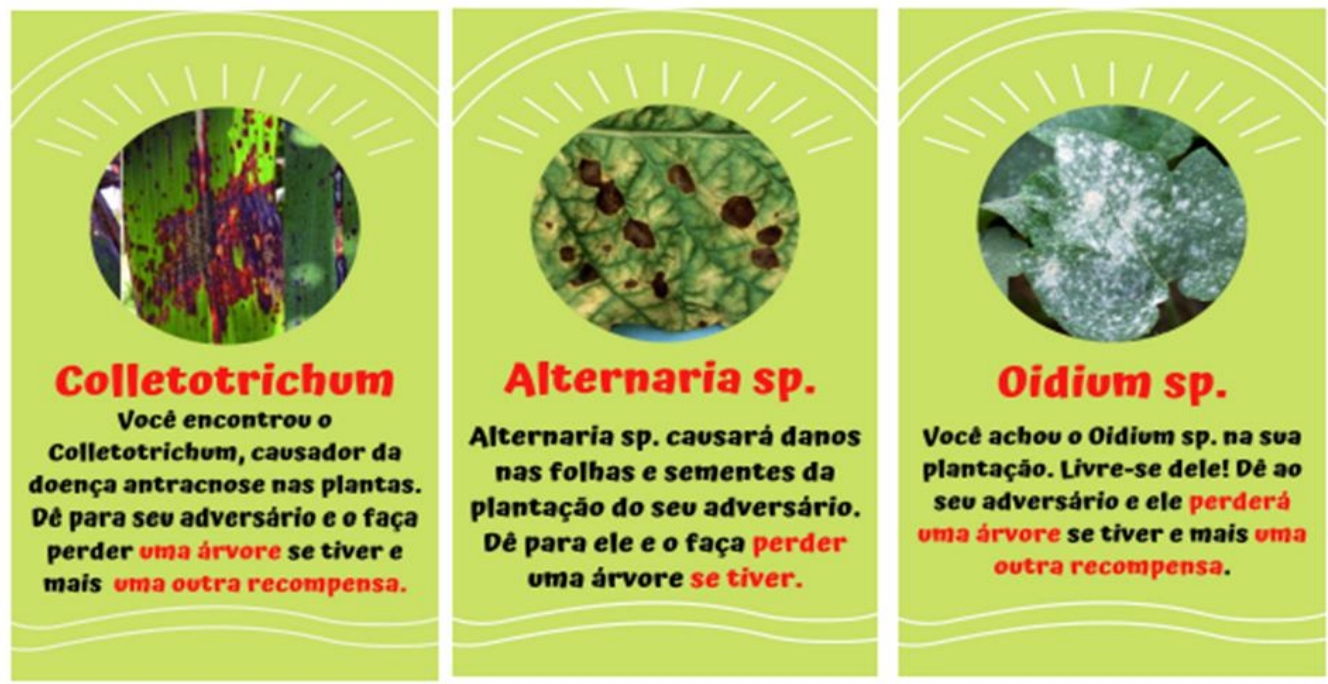

Figura 3: Cartas de fungos vilões.

Fonte: Autoria própria.

\section{Cartas de missões dos fungos}

O grupo de cartas de missões dos fungos trazem informações sobre efeitos benéficos de diferentes espécies ou grupos de fungos e instruções com as possibilidades que o jogador tem para usar a carta imediatamente ou acumular para usá-la depois, sempre com o intuito de resgatar recompensas do tabuleiro (mapa da vila) em troca.

Foram elaborados 8 tipos diferentes de cartas de missões dos fungos, 
para formar esse grupo (Figura 4). Elas contêm a imagem da estrutura macro ou microscópica de espécies ou grupos de fungos; contudo, elas devem ser impressas em quantidades diferentes, seguindo as quantidades indicadas na tabela 2. Nesse grupo, há um total de 30 cartas.

\section{Cartas de vegetação da Caatinga}

As cartas de vegetação da Caatinga apresentam 4 espécies arbóreas nativas da Caatinga. São elas: aroeira (Myracrodruon urundeuva Allemão), angico (Anadenanthera colubrina (Vell.) Brenan), catingueira (Cenostigma pyramidale (Tul.) Gagnon \& G.P.Lewis) e umburana (Amburana cearensis (Allemão) A.C.Sm).

Quando o jogador pegar uma dessas cartas, deve guardá-la como carta premiada que equivale a uma carta do grupo de recompensa. Assim, cada carta desse grupo que o jogador tenha, equivale a mais um ponto obtido na partida.

Foram elaborados 4 tipos de cartas de vegetação da Caatinga, para esse grupo de cartas é impresso somente 1 carta de cada tipo. Então, serão 4 cartas de recompensa vegetal (Figura 5).

\section{Cartas de recompensa}

As cartas de recompensas apresentam diferentes de produtos ou serviços ecossistêmicos realizados pelos fungos nos diversos ambientes representados no tabuleiro, que devem ser conquistadas no jogo. Elas têm formato quadrado e devem ficam dispostas no tabuleiro (mapa da vila), nas áreas relacionadas aos ambientes do tabuleiro representados nas figuras e com descrição textual correspondente.

Foram elaborados 14 tipos diferentes de cartas de vegetação da Caatinga, que devem ser impressas nas quantidades indicadas na tabela 2. Esse grupo é constituído por um total de 15 cartas (Figura 6).

Cada carta desse grupo que o jogador tenha ao final do jogo corresponde a um ponto obtido na partida. Ganha o jogador que obtiver mais pontos no jogo. 

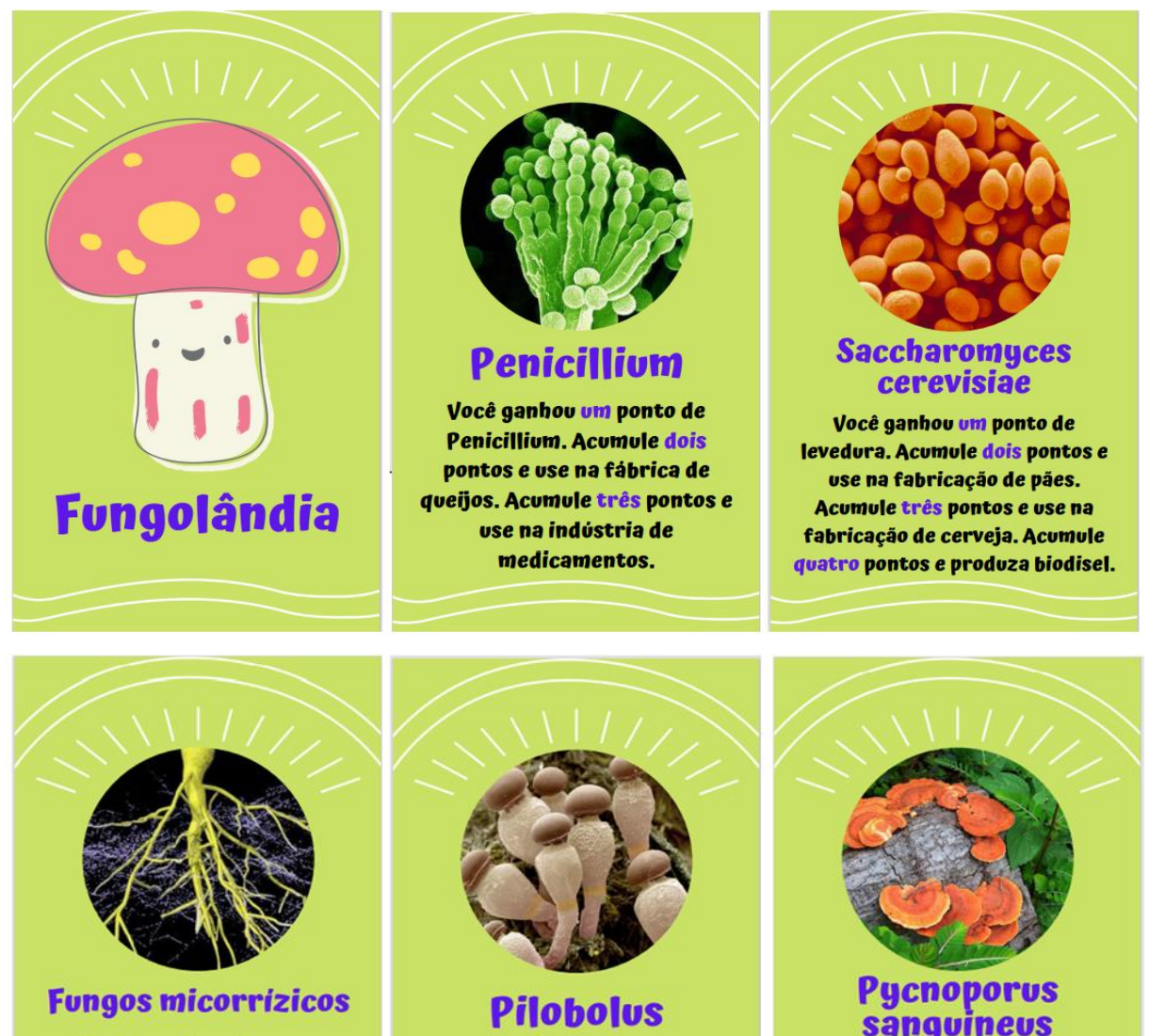

Fungos micorrizicos

Você ganhou fungos micorrizicos. Use para nutrir a plantação $e$ colete um conjunto de frutos.

Use o Pilobolus para ajudar na decomposição de um dos excrementos animais na fazenda.
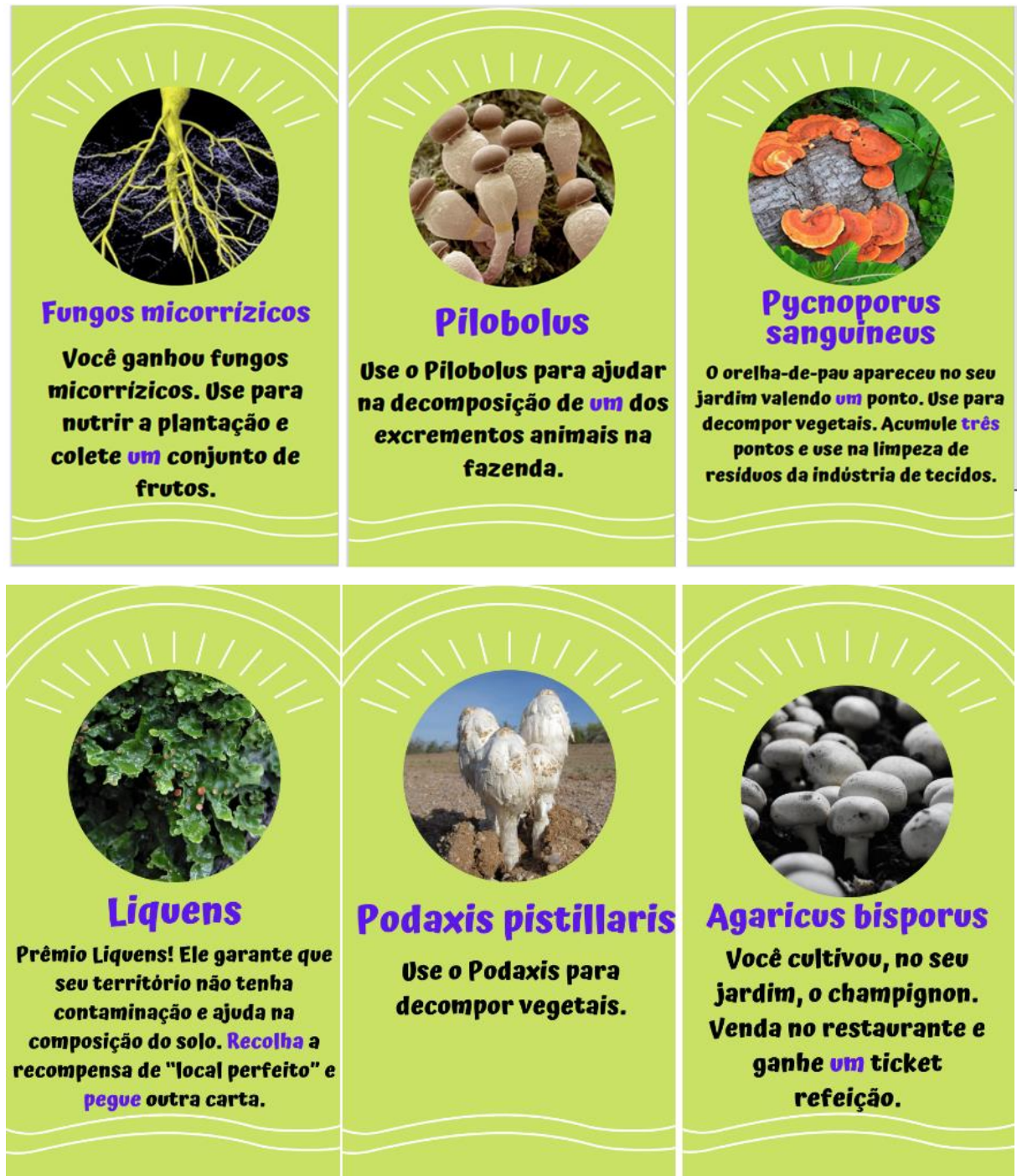

Figura 4: Cartas de missões dos fungos.

Fonte: Autoria própria. 


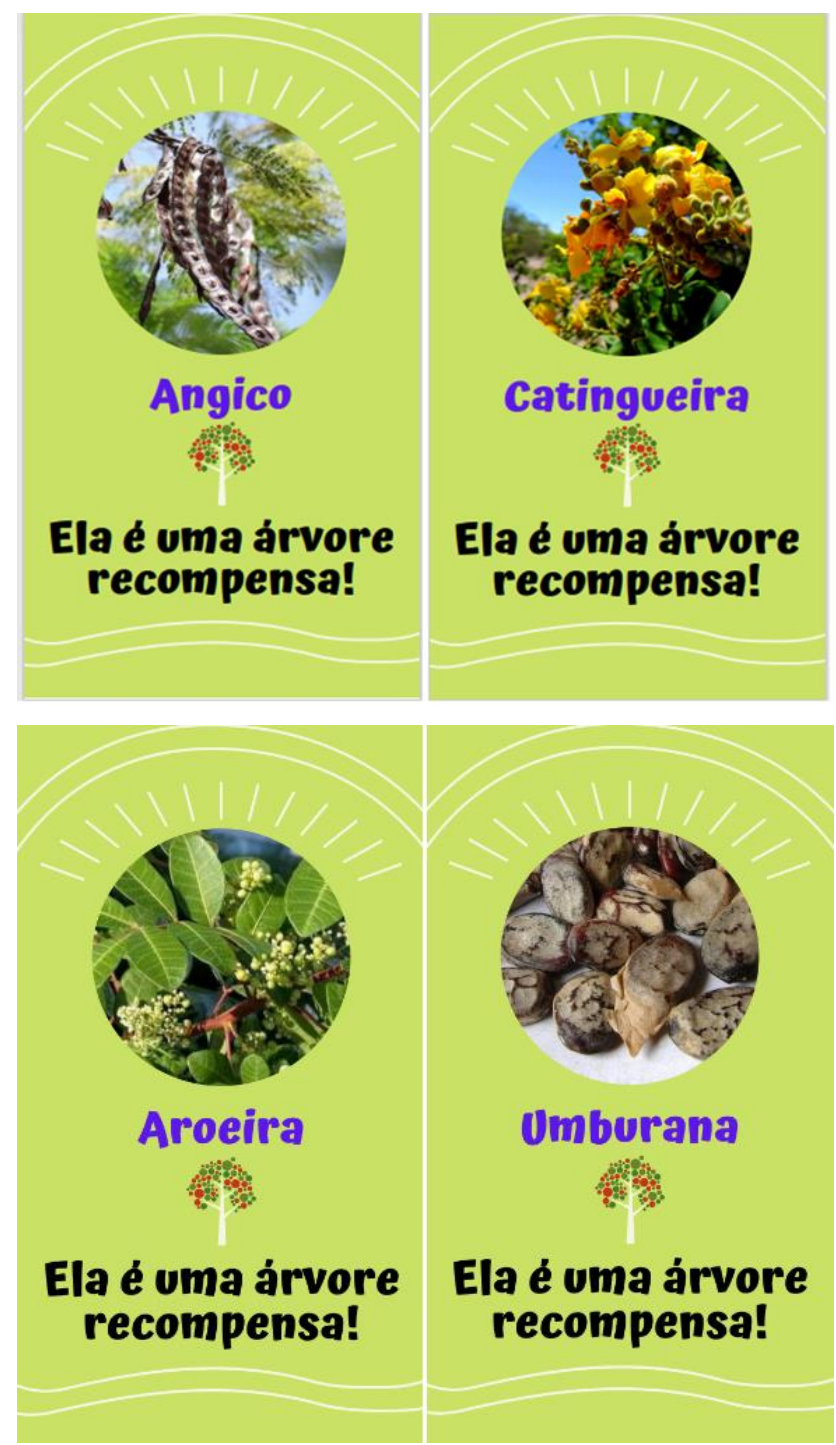

Figura 5: Cartas de vegetação da Caatinga, válidas como pontuação de recompensa, e verso. Fonte: Autoria própria. 

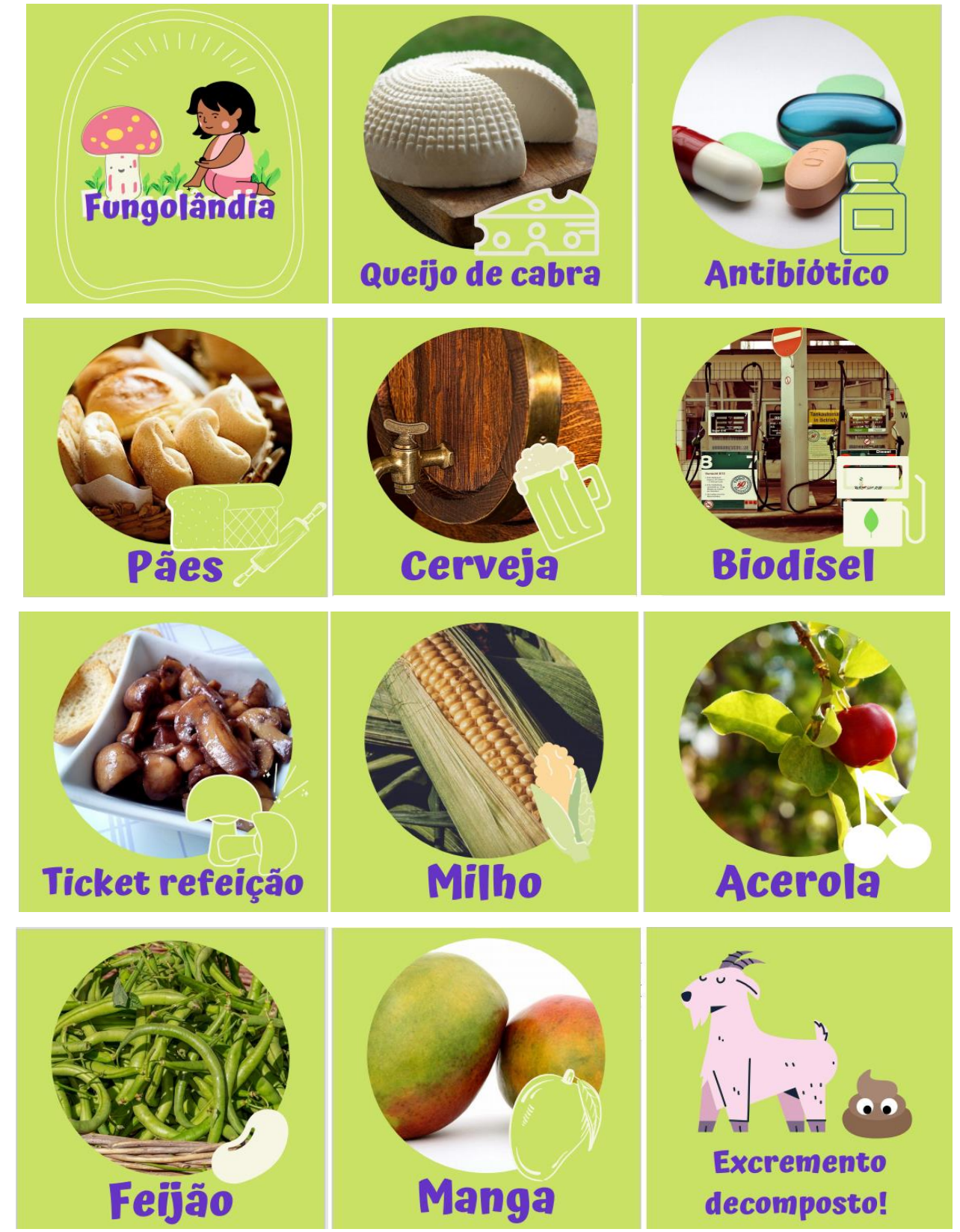

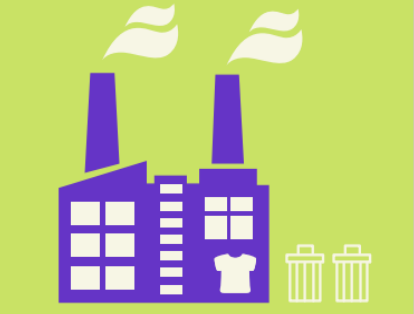

Lixos da fábrica de tecidos tratados corretamente!

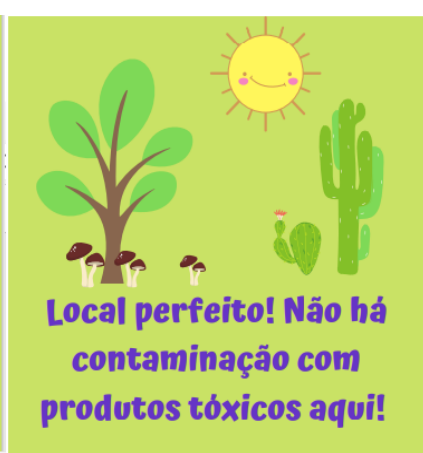

Figura 6: Cartas de recompensas do jogo Fungolândia: verso e frente das cartas. Fonte: Autoria própria.

Revbea, São Paulo, V. 15, № 6: 52-78, 2020. 


\section{Regras do Fungolândia}

Foram criadas regras para o jogo, explicando a utilização do tabuleiro e das cartas (Figura 7). No cartaz com as regras do jogo Fungolândia, está apresentada a dinâmica das partidas, desde o inicio até a finalização de uma partida, bem como o número recomendado de jogadores, explicação sobre a utilização do tabuleiro e das cartas.

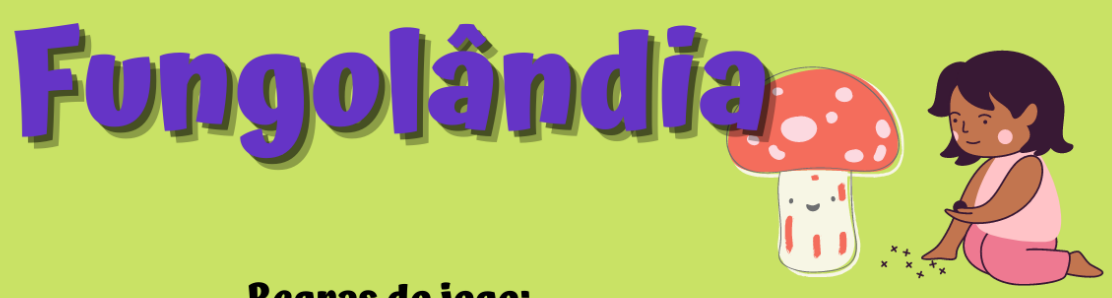

Regras do jogo:

- Cada partida contará com 2 ou 3 jogadores;

- As cartas da pilha de missões devem ficar viradas para ninguém vê-las;

- As cartas de recompensas devem ficar em seus lugares no mapa;

- Na vez do jogador, ele pegará a do topo das cartas de missões viradas e escolherá sua ação;

- Quando o jogador deseja acumular a carta para ganhar uma recompensa depois, a carta permanece em sua mão;

- Quando a pilha de cartas acaba antes do jogo terminar, pega as da pilha de descarte e embaralha-as novamente;

- Quando um jogador ganha uma recompensa, coloca perto de si para a contagem final do jogo;

- Quando o jogador lança um fungo vilão, ele é quem escolherá a recompensa que quer ganhar do adversário;

- 0 jogo acaba quando as recompensas acabam no mapa;

- O vencedor é quem tem o maior número de recompensas acumuladas.

Figura 7: Cartaz com regras do jogo Fungolândia: jogo educativo de tabuleiro sobre a diversidade e importância dos fungos na Caatinga.

Fonte: Autoria própria.

De modo geral, no jogo, os participantes deverão pegar cartas de acordo com sua vez de participar e então realizar o que elas propõem, associando a função dos fungos com o serviço que ele pretende realizar.

Antes de iniciar o jogo, os alunos devem receber o cartaz contendo as 
regras, o tabuleiro e as cartas, para leitura e ciência das regras. Recomenda-se que as partidas tenham entre 2 e 3 jogadores. Durante o jogo, os participantes devem contar com o monitoramento dos professores.

\section{Descrição da dinâmica do jogo}

A partida tem início após a distribuição das cartas de recompensa no tabuleiro e o agrupamento e embaralhamento das cartas das missões dos fungos, cartas de fungos vilões, cartas de vegetação. A pilha deve ficar com o verso das cartas para cima.

Um participante inicia o jogo pegando, de forma aleatória, três cartas na pilha. As informações das cartas indicarão a ação que o jogador fará na sua rodada, visando conseguir as recompensas distribuídas no tabuleiro.

Depois de finalizar as ações da sua jogada, o jogador deve colocar suas cartas numa pilha de descarte e passar a vez para o próximo participante retirar suas cartas e fazer suas jogadas, conforme as instruções nas cartas.

Os jogadores se revezam na partida, sempre com o objetivo do jogo de conquistar recompensas, e o jogo prossegue dessa forma até que acabem as recompensas no tabuleiro. Vence quem obtiver o maior número de cartas recompensas.Caso a pilha de cartas acabe antes do jogo terminar, deve-se pegar as cartas da pilha de descarte, embaralhá-las e reintroduzi-las no jogo.

Fungolândia tem por finalidade auxiliar o professor em uma atividade prática para construção de conhecimentos sobre os fungos, devido a sua complexidade em abordar esse tema em sala de aula de maneira dinâmica, fazendo com que os alunos percebam a importância dos fungos e seus serviços ecossistêmicos, tudo isso levando em consideração a Caatinga e sua biodiversidade. Com uma metodologia diversificada, esse jogo pode despertar o interesse e a curiosidade dos estudantes para a construção de conceitos científicos significativos e valorização da biodiversidade da Caatinga, que podem ser levados para a sua vida, contribuindo para conservação desse ecossistema.

\section{Conclusões}

Os jogos didáticos são ferramentas importantes que favorecem o aprendizado e o desenvolvimento de forma lúdica. O jogo Fungolândia dá oportunidade para 0 aluno aprender brincando sobre os serviços ecossistêmicos dos fungos e meio ambiente. Dessa forma, cumpre a função educativa e auxilia o professor na abordagem desse conteúdo na escola.

Fungolândia é dotado de diversas estratégias para fortalecer o aprendizado sobre os fungos e suas relações com o meio ambiente e com seu uso biotecnológico, sendo uma estratégia didática importante para abordar esses conteúdos no Ensino Fundamental. 


\section{Agradecimentos}

Ao Programa de Pós-graduação em Ciência e Tecnologia Ambiental (PPGCTA) da Universidade de Pernambuco Campus Petrolina.

À Coordenação de Aperfeiçoamento de Pessoal de Nível Superior (CAPES), Brasil - Código de Financiamento 001.

À Fundação de Amparo à Ciência e Tecnologia do Estado de Pernambuco (FACEPE) pela concessão de bolsas e financiamento do projeto "Aprendendo sobre o valor da biodiversidade da Caatinga e seus serviços ecossistêmicos no ensino escolar" (FACEPE APQ - 0177-2.05/18).

\section{Referências}

ASSOCIAÇÃO CAATINGA. Bioma Caatinga. 2020. Disponível em: https://www.acaatinga.org.br/sobre-acaatinga/?gclid=Cj0KCQjwwuD7BRDBARIsAK 5YhUNIVed1EpaXFdl9bJx077R WpytXSqumKJ2yF0Y6FiLpDHY47V9HrsaAuDiEALw wcB. Acesso em: 1 de outubro de 2020.

BARBOSA-SILVA, A.M.; SILVA, A.C.; PEREIRA, E.C.G.; BURIL, M.L.L.; SILVA, N.H.; CÁCERES, M.E.S.; APTROOT, A.; BEZERRA-GUSMÃ̃ M.A.; Richness of lichens consumed by Constrictotermes cyphergaster in the Semiarid Region of Brazil. Sociobiology v. 66, n. 1, p. 154-160, 2019. https://doi.org/10.13102/sociobiology.v66i1.3665

BRASIL. Lei no 9.795, de 27 de abril de 1999. Política Nacional de Educação Ambiental. Disponível em: http://www.planalto.gov.br/ccivil 03/leis/l9795.htm. Acesso em: 22 de julho de 2020.

BRASIL. Serviços ecossistêmicos. Ministério do Meio Ambiente - MMA, Brasília, $2018 . \quad$ Disponível em: https://www.mma.gov.br/biodiversidade/economia-dos-ecossistemas-e-dabiodiversidade/servi\%C3\%A7os-ecossist\%C3\%AAmicos.html Acesso em: 22 de julho de 2020.

BRASIL. Caatinga. Ministério do Meio Ambiente - MMA. Brasília, 2020. Disponível em: https://www.mma.gov.br/biomas/caatinga.html. Acesso em 1 de outubro de 2020.

BREDA, T.V.; PICANÇO, J.L. Jogo de tabuleiro "Conhecendo o Parque Ecológico" como recurso lúdico e educacional em geociências. 2015. Disponível em: http://abrapecnet.org.br/atas enpec/viiienpec/resumos/R00371.pdf Acesso em: 1 de outubro de 2020.

CONAMA, Conselho Nacional do Meio Ambiente, Ministério do Meio Ambiente. Resolução no 001, de 23 de janeiro de 1986. Disponível em: http://www.mma.gov.br/port/conama/res/res86/res0186.html Acesso em: 04 de outubro de 2020. 
DRECHSLER-SANTOS, E.R.; SANTOS, P.J.P.; GIBERTONI, T.B.; CAVALCANTI, M. A. Q. Ecological aspects of Hymenochaetaceae in an area of Caatinga (semi-arid) in Northeast Brazil. Fungal Diversity v. 42, p. 71-78, 2010. https://doi.org/10.1007/s13225-010-0021-9

DOMICIANO, M. F. I. Controle alternativo da antracnose na pimenta (Capsicum spp.) causada por fungo do gênero Colletotrichum gloeosporioides. Minas Gerais, 2019. Disponível em: http://repositorio.ufu.br/bitstream/123456789/29041/3/ControleAlternativoAntrac nose.pdf. Acesso em: 17 de outubro de 2020.

ESPOSITO, E.; AZEVEDO, J.L. Fungos: uma introdução à biologia, bioquímica e biotecnologia. 2 ed. Caxias do Sul: Educs, 2010.

FALKOSKI, L. Experiências pedagógicas em educação ambiental. Eventos Pedagógicos. $2020 . \quad$ Disponível em http://sinop.unemat.br/projetos/revista/index.php/eventos/article/view/4116/278. Acesso em: 14 de Outubro de 2020.

FREIRE, N.C.F.; MOURA, D.C.; SILVA, J.B.; MOURA, A.S.; MELO, J.I.M.; PACHECO, P. Atlas das caatingas: o único bioma exclusivamente brasileiro. Recife: Fundação Joaquim Nabuco, Editora Massangana, 2018.

GRÜBEL, J.M.; BEZ, M.R. Jogos Educativos. Renote, v. 4, n. 2, p. 1-7, 2006.

LIMA, C.E.P.L.; SANTANA, A.S.; MERGULHÃO, A.C.E.S.; LIMA, R.L.F. A. Micorriza arbuscular: alternativa para uso na agricultura sustentável. In: FIGUEIREDO, M.V.B. et al. Tecnologias potenciais para uma agricultura sustentável. Recife: Ipa/Emater/Seagri-AL, 2013.

LUCHETA, F. et al. Comunidade de liquens corticícolas em um gradiente de urbanização na Bacia Hidrográfica do Rio dos Sinos, no sul do Brasil. Rodriguésia, v. 69, n. 2, p. 323-334, 2018.

KAVANAGH, K. Fungi: biology and applications. London: John Wiley \& Sons. 2005.

MAIA, L.C. Fungos do Parque Nacional do Catimbau. Recife: Editora UFPE, 2014.

MENEZES, I.S.; FREITAS, S.H.S.; CARA, P.A.A.; COUTO-SANTOS, A.P.L. Jogo didático como ferramenta para a Educação Ambiental no município de Itapetininga (BA). Revista Brasileira de Educação Ambiental (RevBEA), v. 11, n. 5, p. 19-29, 2016. https://doi.org/10.34024/revbea.2016.v11.2181

MIRANDA, S. Do fascínio do jogo à alegria do aprender nas séries iniciais. Ciência hoje, v. 28, n.168, p. 64-65. São Paulo: Papirus, 2001.

PEIXOTO, A.L.; LUZ, J.R.P.; BRITO, M.A. Conhecendo a biodiversidade. Brasília: Vozes, 2016.

PUTZKE, J. Cogumelos no Sul do Brasil. Estrela: Casa das Letras, 2014. REIGOTA, M. O que é educação ambiental. São Paulo: Brasiliense, 2017. 
SILVA, C.J.A.; MALTA, D.J.N. A importância dos fungos na biotecnologia. Caderno de Graduação - Ciências Biológicas e da Saúde, v. 2, n. 3, p. 4966, 2016.

SILVA, J.M.C.; LEAL, I.R.; TABARELLI, M. Caatinga: the largest tropical dry forest region in South America. Cahm: Springer International Publishing, 2017.

SILVA, P.C.G.; MOURA, M.S.B.; KIILL, L.H.P.; BRITO, L.T.L.; PEREIRA, L.A.; SÁ, I.B.; CORREIA, R.C.; TEIXEIRA, A.H.C.; CUNHA, T.J.F.; GUIMARÃES FILHO, C. Caracterização do semiárido brasileiro: Fatores naturais e humanos. In: Sá, I.B.; SILVA, P.C.G. (Eds.), Semiárido brasileiro: Pesquisa, desenvolvimento e inovação. Petrolina: Embrapa Semiárido, 2010.

SILVA, S.S., IZABEL, T.S.S., GUSMÃO, L.F.P., 2014. Fungos conidiais associados a substratos vegetais submersos em algumas áreas do bioma Caatinga.

Disponível

em:

https://www.scielo.br/scielo.php?script=sci arttext\&pid=S2175-

78602014000200014\&lng=pt\&tlng=pt Acesso em: 14 de Outubro de 2020.

SMITH, S.E.; READ, D.J. Mycorrhizal Symbiosis. 3 ed. San Diego: Elsevier. 2008.

SPIELMANN, A.A. Fungos Liquenizados. São Paulo: Instituto de Botânica IBt., 2006.

STOFELL, S.C.G., et al. Micorrizas arbusculares no crescimento de leguminosas arbóreas em substrato contendo rejeito de mineração de carvão. CERNE. v. 22, n. 2, 2016.

TABARELLI, M., LEAL, I.R., SCARANO, F.R., SILVA, J.M.C. Caatinga: legado, trajetória e desafios rumo à sustentabilidade. Ciência e Cultura v. 70, p. 25-29. 2018.

TEIXEIRA, M.N. O sertão semiárido. Uma relação de sociedade e natureza numa dinâmica de organização social do espaço. Sociedade e Estado, v. 31, n. 3, p. 769-780, 2016.

VICHIATO, B.T.; LIMA, P.J. A educação ambiental a partir de jogos: aprendendo de forma prazerosa e espontânea. p. 1-13, 2011. 